\title{
Activation and Monitoring of Customer Internet Networks Using GPON Technology on PT. Moratelematika Indonesia
}

\author{
Iwan Aramico \\ Informatics and Computer Engineering \\ Jakarta State Polytechnic \\ Depok, Indonesia \\ iwan.aramico.tik15@mhsw.pnj.ac.id
}

\begin{abstract}
Along with the rapid development of science and technology, it will directly or indirectly affect the telecommunications system. The internet is one of the important parts of the telecommunications system that continues to increase and has become a necessity for many people throughout the world. The survey conducted by APJII shows that internet users in Indonesia in 2017 reached 143 million with an increase of $\mathbf{1 0}$ million users from the previous year. This shows that almost all aspects of life are touched by digital internet, with the internet will facilitate work by speeding up processing time and increasing effectiveness. On this basis, it requires technology that can support reliable access services to serve those needs. The technology intended is GPON (Gigabit Passive Optical Network), the latest access device which is one of the various optical fiber communication system technologies. PT. Moratelematika Indonesia is a company engaged in telecommunications and information services that applies the use of GPON technology in providing services to customers. This paper will explain how to present internet services using GPON technology provided by PT. Moratelematika Indonesia to fulfill internet needs for residential and business customers.
\end{abstract}

Keywords-activation, monitoring, GPON technology

\section{INTRODUCTION}

Did you know that Indonesia is the fifth largest internet user in the world? The internet has become a necessity for Indonesia society with a growing number of users every year. In fact, the United Nations (UN) recognizes the internet as a basic right that can be enjoyed by everyone. Almost all aspects of life have been touched by the internet. The internet has been widely used in various fields such as education, health, transportation, entertainment and others. This makes the internet a necessity because it can simplify and speed up work. Therefore, a type of technology is needed that is able to provide internet services with high speed and low costs. The technology intended is Gigabit Passive Optical Network (GPON), the latest access device which is one of the various optical fiber communication system technologies. Internet provider companies that use GPON technology in providing their services, one of which is PT. Moratelematika Indonesia. So as to fulfill internet needs for many people, PT. Moratelematika Indonesia offers a variety of internet services using GPON technology which has the highest speed, longest life, lowest cost network infrastructure available on the market.

\section{LITERATURE REVIEW}

\section{A. Gigabit Passive Optical Network (GPON)}

Gigabit Passive Optical Network (GPON) is a broadband access technology that uses fiber optic cables [1]. GPON uses standardized PON-based optical fiber access network technology by ITU-T (ITU-T G.984 series) [2]. GPON can be described as an optical fiber (optical splliter) point-tomultipoint network that functions as a data distributor for several purposes.

\section{B. Working Principles of GPON Technology}

The working principle of GPON is when data or signals are sent from OLT, then there is a splitter device that serves to allow a single optical fiber to send to various ONU/ONT. This splitter serves to divide or transmit data or signals and allows a single optical fiber to send signals or data to various ONU / ONT. Then from the side of the ONT will provide data and signals desired by the user. GPON is basically a technology for point-to-multipoint relationships, and this topology is suitable for serving groups of customers located separately. GPON reduces the use of many cables and equipment at the head office when compared to point-to-point architecture [2].

\section{GPON Devices}

Based on the configuration of the GPON network device can be divided into several parts, which consist of:

- $\quad$ Network Management System (NMS)

NMS is software that has a function to control and configure GPON devices. Configuration that can be done using NMS on the OLT and ONT side. NMS has a direct path to OLT, so that NMS can monitor ONT and OLT remotely [1].

- $\quad$ Fiber Optic Cables

A fiber optic cable is a network cable that contains strands of glass fibers inside an insulated casing. They're designed for long distance, high-performance data networking and telecommunications. The type of optical fiber used in GPON that is applied for long distance communication must have the ability to carry many signals with high bit rates. Of the two types of optical fibers that exist, namely single mode and multimode type, which is used as a transmission medium GPON technology is a type of single mode, this is because the single mode mode wave work area is higher than the multimode type [3]. 
- $\quad$ Optical Line Termination (OLT)

Optical Line Termination (OLT) as the central area of a network system. OLT is a combination of CWDM, Gigabit-capable Ethernet (GbE) and SONET / SDH which is used to transmit sound, data and video through the Gigabit Passive Optical Network (GPON). OLT has a function to convert from electrical signals to optics. OLT provides an interface between the GPON system and data network service providers [1].

- $\quad$ Optical Network Terminal (ONT)

Optical Network Terminals (ONT) are on the customer side of the network system. ONT has the main task, which is used to send voice, data, and video through Gigabit-capable Passive Optical Network (GPON) to customers and OLT [4].

- Splitter

Splitter is a passive component that can separate optical power from one fiber input into two or several fiber outputs. The PON splitter is said to be passive because it does not require an external energy source and optimization is not done on the power used on the customer, the distance is different from the node splitter, so the way it works divides optical power equally.

The splitter in GPON technology is said to be passive because it does not require an external energy source and optimization is not done on the power used on the customer whose distance is different from the node splitter. Passive Splitter is a simple optical fiber coupler that divides optical signals into several paths (multiple paths) or combination signals in one path [1].

- $\quad$ Fiber Access Terminal (FAT)

FAT or often referred to as ODP (Optical Distribution Point) is a device used by a provider or operator of FTTH as the last terminal to be connected directly to the customer. Usually FAT devices are installed on electrical poles in the customer's environment. FAT installation aims to facilitate the installation of cable lines from the FAT to a number of customer homes, while facilitating installation if there are new customers who will subscribe [5].

\section{ACTIVATION, CONFIGURATION, AND MONITORING OF INTERNET LINKS}

\section{A. Internet Link Activation}

\section{Activation Preparation}

Activation will be carried out if EWO (Engineering Work Orders) is received from the Dispatcher division via email that is equipped with data from the customer. The data consists of the name of the customer, the product / service chosen, and the ONT serial number that explains the vendor's choice. When activating, the team from NOC Provisioning also collaborated with the CTS (Customer Technical Support) team who immediately dropped off the customer's location. To be able to communicate with each other, both the NOC Provisioning team and the CTS team used the Whatshap media application.

The data obtained shows that the customer in the name of PT. Buana Masa Metalindo wants to install internet services and requires activation of new links. The selected product is oxygen $250 \mathrm{Mbps}$ equipped with public IP / 30.

While the network topology series for customers of PT. The Metalindo Masa Buana is as follows:

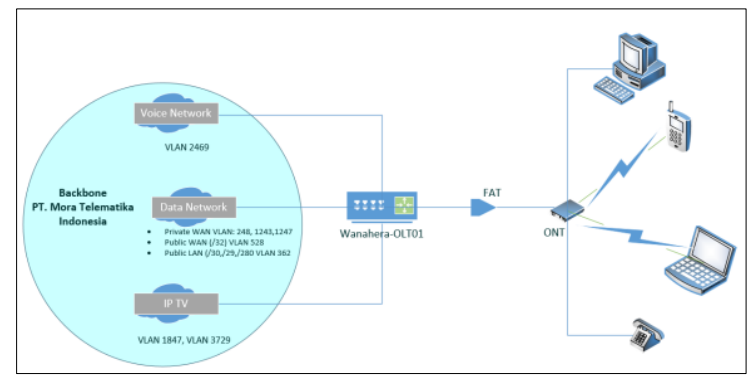

Fig. 1. New Link Activation Topology customer PT. Buana Metalindo

\section{Registration of ONT}

In activating the new link, an ONT registration is required to be installed and leased to the customer. Registration of the ONT will be conducted at moraapps.moratelindo.co.id, which is a web-based application owned by PT. Moratelematika Indonesia. In activating new customers, ONT registration is required by completing data such as vendor choices, serial ONT numbers, product choices, segment categories, and customer names.

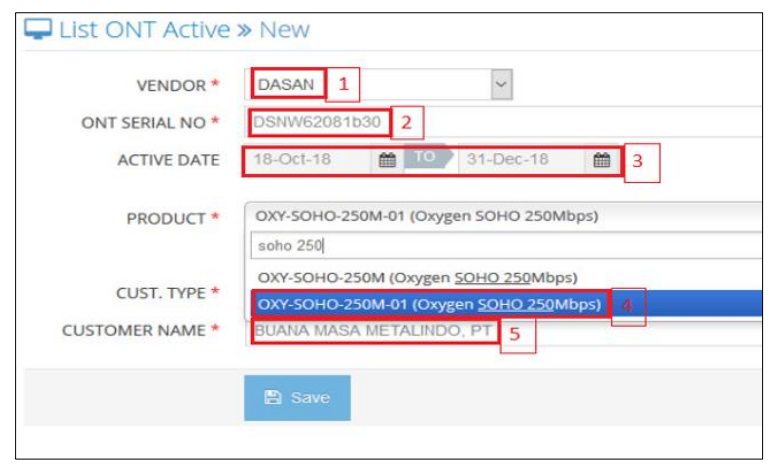

Fig. 2. Registration of ONT

3. Registration and injection of IP Address

Public IP for customers on behalf of PT. Buana Masa Metalindo is located on the 43,243,142.0 network. Because the customer chooses a Public IP with subnet / 30, then there is one public IP that will be given to the customer besides the IP gateway, network, and broadcast. In addition to public IP registration, static IP registration is also required to be applied to the ONT provided to customers. 
So that the data collected on IP registration for customers of PT. The Metalindo Masa Buana is as follows:

TABLE I. CUSTOMER IP ADDRESSING

\begin{tabular}{|l|l|}
\hline Jenis Pengalamatan & IP Address \\
\hline Network & $43.243 .142 .140 / 30$ \\
\hline Gateway & $43.243 .142 .141 / 30$ \\
\hline IP Static & 10.81 .55 .125 \\
\hline
\end{tabular}

Then in the injection of public IP addresses and static IP addresses will be done in the Winbox application which also includes a configuration for BGP routing (Border Gateway Protocol). BGP has the ability to do route collection, route exchange and determine the best route to a location on the network. The BGP protocol has an important role in the process of presenting internet services to customers.

\begin{tabular}{|c|c|c|c|c|c|c|}
\hline \multicolumn{7}{|c|}{ Route Filters } \\
\hline 4 & = & $\checkmark$ & $x$ & $\square$ & $\nabla$ & \\
\hline$\#$ & \multicolumn{2}{|c|}{ Chain } & \multicolumn{3}{|c|}{ Prefix } & Pr \\
\hline \multicolumn{7}{|c|}{ :.: PT. KALIMUTU MITRA PERKASA } \\
\hline \multicolumn{3}{|c|}{17 bras-out } & \multicolumn{3}{|c|}{$122.50 .6 .188 / 30$} & \\
\hline \multicolumn{7}{|c|}{ ::. PT. BORNEO PASIFIK GLOBAL } \\
\hline \multicolumn{3}{|c|}{18 bras-out } & \multicolumn{3}{|c|}{$103.83 .94 .32 / 30$} & \\
\hline \multicolumn{7}{|c|}{ ::. BUKALAPAK.COM , PT( site freeware) } \\
\hline & br & -out & \multicolumn{3}{|c|}{$103.78 .81 .232 / 29$} & \\
\hline \multicolumn{7}{|c|}{ :.: NOVIAYANA (PT. Falah Innovation Technology) } \\
\hline & & -out & \multicolumn{3}{|c|}{$103.78 .215 .144 / 30$} & \\
\hline \multicolumn{6}{|c|}{$\therefore$ BUANA MASA METALINDO. PT } & \\
\hline \multicolumn{3}{|c|}{21 bras-out } & \multicolumn{3}{|c|}{$43.243 .142 .140 / 30$} & \\
\hline \multicolumn{7}{|c|}{ :.. SETIA BUDHI-DSINW6208a388 } \\
\hline \multicolumn{3}{|c|}{22 bras-out } & & 56.2 & $3.0 / 30$ & \\
\hline \multicolumn{7}{|c|}{ :.: DEDI ISKANDAR } \\
\hline
\end{tabular}

Fig. 3. IP Injection Results on Winbox

\section{B. Configuring Internet Links}

1. Configuration Preparation

In configuring the tools that will be used is SecureCRT. SecureCRT is an application used to configure OLT devices remotely. The configuration for New Link activation will be done after checking information about the ONT. This information regarding active / deactive ONT status, port layout, ONU id, serial number, ONT distance to OLT, attenuation, and service product type.

2. Configuring Internet Links

Basically the configuration carried out has been based on the previous configuration by adjusting the type of device from the vendor used. An XML file that was created from the previous configuration contains the general configuration of the device. Thus the configuration process is made easier by applying XML files on the device. An XML file containing configuration from the ONT can be applied to the
OLT after knowing the information about the status of the device.

The following is a command for configuring XML files to be applied to OLT.

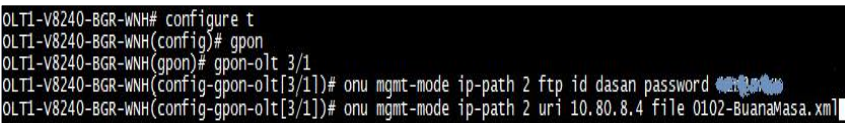

Fig. 4. Configuring XML files

\section{Service Monitoring}

1. Monitoring Preparation

In monitoring services using the The Dude application. The monitoring process can be carried out if the activation and configuration process has been completed. The IP address that will be monitored is the IP of the gateway that leads directly to the customer ONT.

2. Monitoring Using The Dude Application

The Dude will be used to monitor networks that are connected to customers. Monitoring is needed to know the status of the device as a whole and in real time [6]. The activity and status of the device are described in different colors on the The Dude application. The color display consists of green, blue, and red. For device status, blue indicates that there is an inactive service. On a device with a red status indicates that the device is off or disconnected from the network. Whereas for devices with green status indicates that all services on the device are running properly.

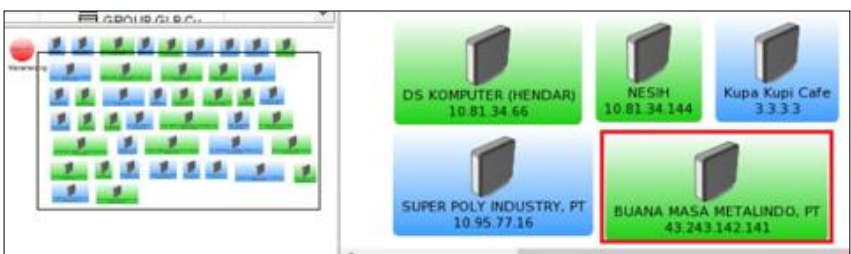

Fig. 5. Monitoring on The Dude Application

\section{INTERNET NETWORK TESTING}

The testing process is needed to ascertain whether the internet network installed has been running properly. The testing process by doing a Ping test. Ping is used to check network connectivity based on TCP / IP protocol. 


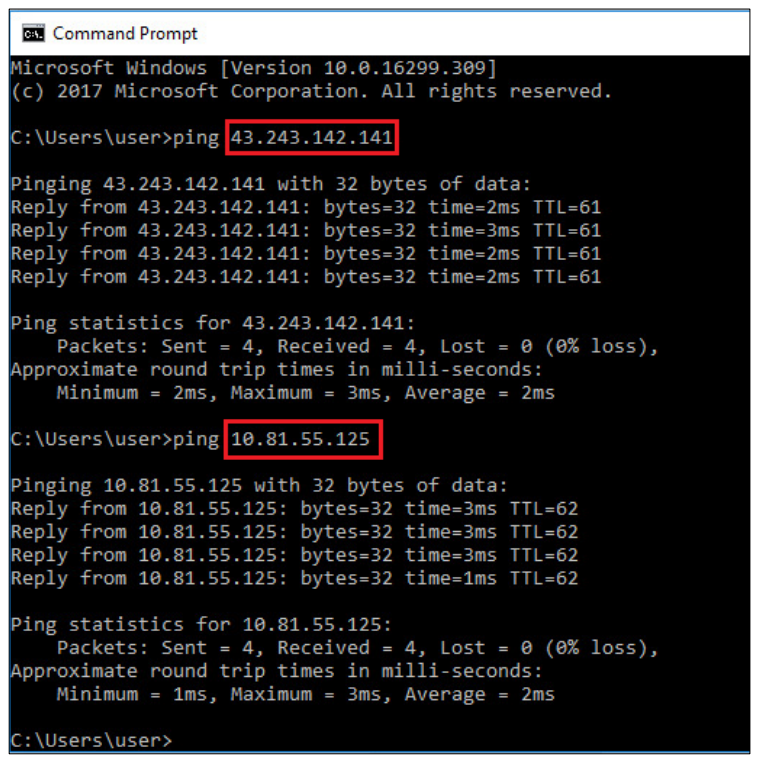

Fig. 6. Ping Testing

The results of the PING process in Figure.6 show the quality of network connectivity. The Ping process observed for the gateway IP 43.243.142.141 and static IP 10.81.55.125 shows that the ping packet is running stable. From each IP has a small packet travel time of about 1-3 ms, with the smaller time needed to show better connectivity. In addition, the quality of network connectivity from each IP is in good condition with no packet loss.

Then it also requires testing of the service capacity presented. This test is in accordance with the service specifications from previous customer requests, namely Oxygen services with speeds of up to $250 \mathrm{Mbps}$. Speed test is needed to find out whether the service presented is in accordance with customer demand.

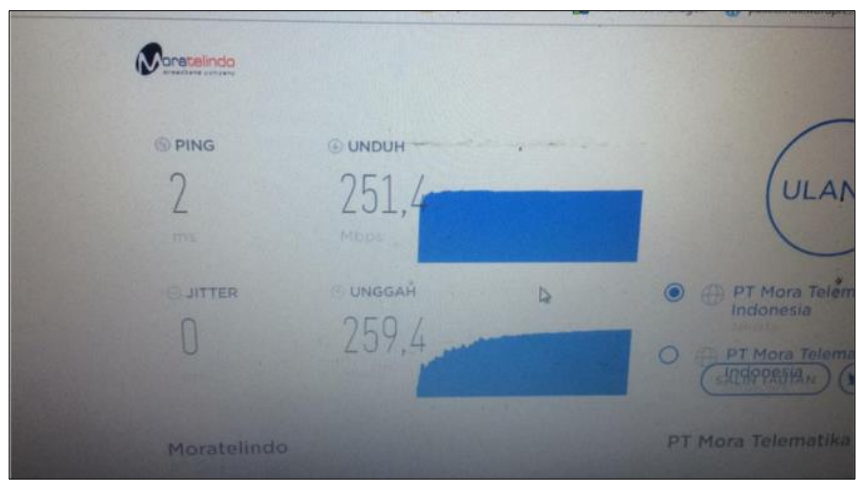

Fig. 7. Speedtest testing

The results of the speedtest test showed that download speeds reached 251.4 Mbps and uploads reached 259.4 Mbps. So that based on the results of the speedtest test shows that the services provided are in accordance with customer requests. Then from the results of monitoring observations for 15 days (October 19, 2018 to November 2, 2018), it shows that there were no problems that occurred on the device or the internet service presented. During the tempo of observation the internet link for customers in the name of PT. Metalindo Buana runs normally.

\section{CONCLUSION}

Based on the results of observations from the research it can be concluded that:

- The use of fiber optic cable based GPON technology can provide the presentation of internet services in accordance with the specifications offered by PT. MoraTel to customers.

- The scheme in presenting GPON-based services is in the form of sending data or signals from the service center via OLT by being forwarded to the splitter. Then the spiltter will send the signal to various ONT devices on the side of the customer.

- The application of GPON as a broadband access technology can make it easier to manage and monitor services presented to customers.

\section{ACKNOWLEDGMENT}

The author would like to say thank you to:

- The parents and family of writers who have provided moral and material support.

- Supervisors who have provided time, energy, and mind to direct the author in preparing reports.

- $\quad$ To all employees of PT. Moratelematika Indonesia who helped a lot.

\section{REFERENCES}

[1] Prayogo, R. S., Rosmiati, M., and Rizal, M. F., "Pembuatan Modul Praktikum FTTH Menggunakan Teknologi GPON untuk Mendukung Pelaksanaan Praktikum Jaringan Serat Optik di Prodi Teknik Komputer Fakultas Ilmu Terapan Universitas Telkom," vo.1 1, pp. 64-73, 2015.

[2] Barus, A., Hafidudin, and Damayanti, T. N., "Perancangan Jaringan Fiber To The Home (FTTH) Menggunakan Gigabite Passive Optical Network (GPON) di Perumahan Cluster Courtyard Karawang," 3rd ed, vol. 1, pp. 161-17, 20171.

[3] Dewi, N. and Hamdani, M., "Perancangan Jaringan FTTB GPON Untuk Layanan Triple Play di Surya Cipta Industri," Jurnal Penelitian dan Pengkajian Sains dan Teknologi, vol. 27, pp. 17-24, 2015.

[4] Kowalke, M., "Optical Network Terminal (ONT) Provisioning Made Simple," http://blog.tmcnet.com/next-generationcommunications/2015/04/optical-network-terminal-ont-provisioningmade-simple.html. [5 Desember 2018]

[5] Toago, S. P., Alamsyah, and Amir, A., "Perancangan Jaringan Fiber To The Home (FTTH) berteknologi Gigabit Passive Optical Network (GPON) di Perumahan Citraland Palu," Jurnal Mektrik, vol.1, pp. 4046, 2014.

[6] Widodo, A., "Implementasi Monitoring Jaringan Komputer Menggunakan Dude,” Jurnal Penelitian Teknologi Informasi, Vol. 11, pp. 1-10, 2015. 